\title{
ARTIGO
}

\section{Escopo e abrangência da Ciência da Informação e a Pós-Graduação na área: anotações para uma reflexão}

\author{
The make up and aim of the Information \\ Science and the Postgraduation in the area of: \\ notes for reflection
}

Maria Nélida GONZÁLEZ DE GÓMEZ1

R E S U M O

\begin{abstract}
A Ciência da Informação não teria como objeto a informação, fora de contexto, constrói seu objeto por um ponto de vista que organiza um domínio de conhecimentos, a partir da articulação informação/ação de informação. Os estratos e modalidades das ações de informação estabelecem novas zonas de vizinhança e solidariedade com outros conhecimentos. Nesse contexto, a pós-graduação resultaria de combinar um programa disciplinar, princípio institucionalizador do domínio, e um programa de pesquisa, inter e trans-disciplinar, orientado à descoberta e à inovação.
\end{abstract}

Palavras-chave: ação de informação, estratos, atores heterogêneos, interdisciplinaridade.

\footnotetext{
${ }^{1}$ Doutora em Comunicação, Linha de Pesquisa em Ciência da Informação. Pesquisadora Titular - IBICT: MCT. Professora da Pós-Graduação em Ciência da Informação da UFRJ e do IBICT. Rua Lauro Muller, 455, 5 andar, 22290-160, Rio de Janeiro, RJ, Brasil. E-mail: nelida@ibict.br

Recebido para publicação em 22/1/2003 e aceito em 12/2/2003.
} 


\section{A B S T R A C T}

The Information Science do not have as an objective 'information', outside the context, it builds its objectives from a point of view that organizes a knowledge domain, through information articulation/action of information. The "layers" and modalities of the action of information, estabilishes new common fields with other fields of knowledge. Therefore the Postgraduate programmes are a combination of a disciplinary programme, that is the domain's institucionalization principle, and a research programme, focussing on development and innovation.

Key words: action of information, layers, heterogeneous actors, interdisciplinarity.

\section{N TRO D U C Ã O}

A Pós-Graduação pode caracterizar-se por uma dupla estrutura de fins: a formação de competências muito complexas e específicas e a participação na produção de conhecimentos científicos - decisiva, no contexto do Brasil. Situa-se, assim, num ponto em que se entrecruzam, por um lado, a formação de recursos humanos, o que a relaciona com os universos do trabalho, e, por outro, a geração de conhecimentos, relacionando-a com os espaços da pesquisa científico-tecnológica.

Neste caso, nos ocuparemos da relação da Pós-Graduação com a produção de conhecimentos científicos e seus desdobramentos em áreas de conhecimentos e setores de demanda.

\section{A definição do escopo e da abrangência da Ciência da Informação}

Em primeiro lugar, deveremos esclarecer que o objeto de estudo da Ciência da Informação não poderia ser, a nosso ver, a informação de maneira não qualificada, como uma objetividade isolada e descontextualizada - quase uma "coisa em si".

A Ciência da Informação, assim, seria aquela que estuda fenômenos, processos, construções, sistemas, redes e artefatos de informação, enquanto "informação" for definida por ações de informação, as quais remetem aos atores que as agenciam, aos contextos e situações em que acontecem e aos regimes de informação em que se inscrevem.

Para melhor conceituação do domínio de construção do objeto da Ciência da Informação, incorporamos à sua definição quatro aspectos principais: os estratos da ação de informação; suas assimetrias e interfaces; as modalidades da ação de informação; os sujeitos das ações de informação; os encaixes e enfeixamento entre as ações de informação e os regimes de informação.

Consideramos, assim, que o que se denomina informação constitui-se a partir das formas culturais de semantização de nossa experiência do mundo e seus desdobramentos em atos de enunciação, de interpretação, de transmissão e de inscrição. Tais condições de possibilidade e de realização de uma ação de informação abrangem, assim, condições, regras e recursos de locução, transmissão, inscrição, decodificação, circunscritas pelas disponibilidades materiais e infraestruturais em que se inscreve a ação. Desse modo, uma pessoa ou grupo pode possuir informações que não conseguem ser passadas ou transmitidas porque não dispõe de recursos de locução, ou não pode transmitir informações que consegue expressar em forma discursiva, por não possuir os meios de inscrição e transmissão. 
As formas singulares da experiência humana em geral, e da científica em particular, estariam condicionadas, assim, pelo enfeixamento dos regimes de verdade (FOUCAULT, 1984), como aqueles que regem os enunciados e a forma como estes se regem entre si, estabelecendo figuras de enunciação que os sustentam como plausíveis de prova ou cientificidade, com os regimes de informação (FROHMANN, 1995; GONZÁLEZ DE GÓMEZ, 1996; 2000), que Ihes darão vigência e ancoragem em sistemas instituídos de inscrição e suas linhas preferenciais de transmissão e interpretação.

Sustentamos, porém, como uma das premissas de nossos estudos, que é próprio aos modos culturais da experiência humana a existência de certa autonomia de decisão e escolha nas práticas e ações de conhecimento e comunicação, de modo que, para cada forma de intersubjetividade, em cada caso e em cada contexto, algo pode e não pode, ao mesmo tempo, cruzar uma linha imaginária que o faz ser considerado ou descrito como "informação".

Num sentido mais preciso, afirmamos que essas instâncias seletivas e decisórias dos sujeitos sociais não operam sobre um campo de informações já constituídas, ex post, mas intervêm na própria constituição de algo a ser designado como informação ou do domínio da informação - ex ante.

Poderíamos dizer assim que o que se denomina hoje como informação, resulta da sobre-determinação de uma "indecidibilidade estrutural", mediante atos ou processos seletivos explícitos e formais ou tácitos e não-formalizados, dos indivíduos e grupos sociais em suas práticas culturais.

No horizonte dessa indeterminação de ponto de partida (do que virá a ser informação perceptual, textual, documentária), chamaremos ações de informação aquelas que estipulam qual é o caso em que a informação é o caso.
Em conseqüência do anterior, afirmaremos que as ações sociais de geração e transferência de informação, ainda que não necessariamente intencionais nem voluntárias, nunca serão totalmente determinadas por condições de natureza biológica, econômica ou tecnológica. Por essa razão, sustentaremos logo que ações de informação tanto podem orientar-se à reprodução quanto à mudança dos regimes de informação que direcionam o fluxo e distribuição de informação entre sujeitos, áreas do conhecimento, atividades e regiões.

Diremos, enfim, que a informação, assim identificada, fica ancorada no tecido social: a) pelo modo de produção de sentido; b) pelo modo de produção e circulação de inscrições; c) pela sua constituição num ponto de enfeixamento de uma rede de atos de enunciação e de um sistema de inscrição e transmissão.

\section{Os estratos da ação de informação: assimetrias e interfaces}

Em primeiro lugar, analisaremos a ação de informação como um conjunto de estratos heterogêneos e articulados. Entendemos que os "estratos", a diferença das "fases", correm de modo paralelo e simultâneo ao longo de todo o desenvolvimento de uma atividade ou processo (Quadro 1).

Um dos estratos, aquele que denominamos "informação" de modo restrito, remete a formações discursivas e a comunidades de informação. É polimórfico, expressivo de todas as heterogeneidades e singularidades dos sujeitos e seus "mundos de vida".

Nessa dimensão, as ações de informação acontecem como ações narrativas, relacionadas às múltiplas formas culturais de produção de sentido, onde são instituídas ontologias classificatórias, e regras e usos dos coletivos de narradores, que estabilizam de modos flexíveis e diversos aquela produção de sentido. 
Um outro estrato, ao qual podemos denominar meta-informacional, de estruturação meta-informacional ou regulatório, é aquele onde se estipula o domínio relacional ou o contexto dentro do qual algo apresenta ou representa um valor de informação. Ao estruturar as modalidades e alternativas de relacionamento entre duas ou mais informações atuais ou virtuais, e entre duas ou mais inscrições documentárias, neste plano ficaria estabelecido o domínio relacional ou o contexto a partir do qual aquilo que adquire caráter de informação, pode desenvolver valores cognitivos, constituir evidências probatórias, servir de apoio a decisão ou ser insumo de ações instrumentais. Denominamos este componente da ação informacional, ação regulatória, de enquadramento, monitoramento e de controle.

Um outro estrato remete àquilo que disponibiliza e deixa disponível, como sua mediação sócio-cultural, um valor de informação, e que poderíamos caracterizar como ação tecno-econômica - de antecipação estruturante na configuração da ação/informação. Para referir- mo-nos a tudo aquilo que, como matéria informada, mediação maquínica ou como passado instituído do mundo social, condiciona e limita uma ação de informação, poderíamos falar de "dispositivo de informação" ou de "artefatos de informação" - ou, preferimos hoje - "objetos relacionais", quando enfatizamos a instância da inscrição e objetivação de um testemunho ou evidência informacional como objeto cultural.

Em geral, poderíamos dizer que essa ação de informação ou complexo de componentes acionais: a) do ponto de vista semântico-pragmático, se constitui conforme regras ou usos, na maior parte das vezes implícitos e habituais nas comunidades de sua geração e transmissão; b) do ponto de vista de sua estruturação metainformacional, responde a normas organizacionais, padrões e contratos - que em geral formalizam alianças e convenções - e c) do ponto de vista das infra-estruturas, atende a princípios estruturadores que resultam ora de modelos, ora de normas técnicas condicionalmente obrigatórias. Daí que tanto problemas quanto propostas de transformação de um

Quadro 1. Os estratos das ações de informação.

\begin{tabular}{|c|c|c|}
\hline Estratos Informacionais & Formas de ação/operação & Normas \\
\hline $\begin{array}{l}\text { Informação } \\
\text { (semântico-pragmática) }\end{array}$ & $\begin{array}{l}\text { Estrato polimórfico. } \\
\text { Definido nos mundos de vida, em todos os } \\
\text { setores de atividade: da educação, das } \\
\text { artes, das ciências, da produção, dos mer- } \\
\text { cados. }\end{array}$ & $\begin{array}{l}\text { Ações narrativas. } \\
\text { Ontologias, classificações, re- } \\
\text { gras/usos. }\end{array}$ \\
\hline Estruturas de meta-informação & $\begin{array}{l}\text { Estrato regulatório. } \\
\text { Definidas nos espaços institucionais e } \\
\text { regulatórios do Estado, da Administração } \\
\text { Pública, do campo científico, da educação } \\
\text { formal. }\end{array}$ & $\begin{array}{l}\text { Ações regulatórias, de controle } \\
\text { e monitoramento. } \\
\text { Leis, patentes, contratos, pa- } \\
\text { drões. }\end{array}$ \\
\hline $\begin{array}{l}\text { Infraestruturas de informação } \\
\text { Objetos de informação }\end{array}$ & $\begin{array}{l}\text { Estrato mimeomórfico. } \\
\text { Definido na indústria e nos mercados das } \\
\text { tecnologias, das máquinas e dos produtos. }\end{array}$ & $\begin{array}{l}\text { Ações tecnoeconômicas. } \\
\text { Normas técnicas, modelos. }\end{array}$ \\
\hline
\end{tabular}


domínio de ações de informação, terão que ser situados em seu justo estrato de ocorrência e princípios de constituição. Problemas de interação entre sistemas, por exemplo, podem resolver-se muitas vezes no estrato dos padrões e contratos, não necessariamente por modelagens alternativas ou no plano das normas técnicas.

Podemos tratar de melhorar essa conceitualização da informação pela reconstrução do que sejam "ações de informação". Relacionaremos, com esse fim, "ação social" e "forma de vida" (tal como equacionadas por Harry Collins), entendendo que uma "forma de vida" pode estar constituída pelas interações duradouras de um grupo que partilha de atividades, situações e experiências comuns (GEERTZ, 1998).

Collins \& Kush (1999) denominam "ações formativas" aquelas que são constitutivas de uma "forma de vida", a qual singularizam e diferenciam em relação a outros modos de ação e formas de vida. Assim, os atores sociais, "(...) estão de acordo em seus conceitos porque eles partilham uma realidade de ações possíveis e estão de acordo em suas ações porque eles partilham uma rede comum de conceitos" (COLLINS \& KUSH, 1999, p.11).

Uma ação formativa, por exemplo, na academia, é apresentar uma comunicação num congresso. Numa comunidade religiosa, assistir ao culto. As instituições, nesse quadro, se constituem como variáveis com diversos graus de valor, de modo que pode estender-se de uma ação instituente, com um mínimo de acordo entre os participantes a uma ordem instituída e formalizada, que pode ser coercitiva e de pretensões totalizadoras em seu domínio de intervenção. O que "fixa" um significado, um discurso, ou pode pré-configurar um "artefato de informação" em alguma de suas dimensões, não seria logo e em primeiro lugar a base material da inscrição, e sim as condições institucionais e as relações socioculturais entre os sujeitos - incluídas as relações de poder que articulam os artefatos e as infraestruturas de informação em regimes de informação.

Estratos ou dimensões das ações de informação admitem outra leitura, conforme se trate de ações polimórficas ou ações mimeomórficas (COLLINS \& KUSH, 1999, p.19).

Ações polimórficas são aquelas que só podem ser compreendidas por quem participa de uma cultura ou forma de vida. Nesse caso, a mesma ação, na mesma situação, pode ser executada conforme um número indefinido de comportamentos e, ao mesmo tempo, uma mesma instância de comportamento pode dar lugar a muitas e diferentes ações. Dado que são ações determinadas por regras, o modo "correto" de realizá-las só é possível para quem participa da forma de vida que é o contexto da ação. O prefixo poli conota "pluralidade" (mayness), referindo-se aos múltiplos comportamentos que podem corresponder a uma mesma ação, assim como aos múltiplos sujeitos implicados (como referência ao social, à polis).

Ações mimeomórficas seriam aquelas que poderiam ser reproduzidas tanto por um observador externo - alguém que não compreende sua intencionalidade nem seu contexto de geração -, quanto por quem compreende a ação (COLLINS \& KUSH, 1999, p.21).

São tipos de ações pré-modeladas que podem apreender-se através de exemplos, por treinamento. Tal como discar num telefone ou "clicar" um ícone do Windows.

A partir destas considerações, diremos que práticas e atividades sociais de informação são combinações híbridas de ações polimórficas e mimeomórficas. Daí que sistemas, redes e artefatos de informação resultam da busca de um modo de equacionar as condições da base tecnológica, que reúne componentes operacionais e componentes comportamentais mimeomórficos, os quais são de caráter genérico e com baixa potência de singularização, junto a demandas e conteúdos culturais da máxima plasticidade e polimorfismo (Quadro 2). 
Quadro 2. Assimetrias e encaixes dos estratos da informação.

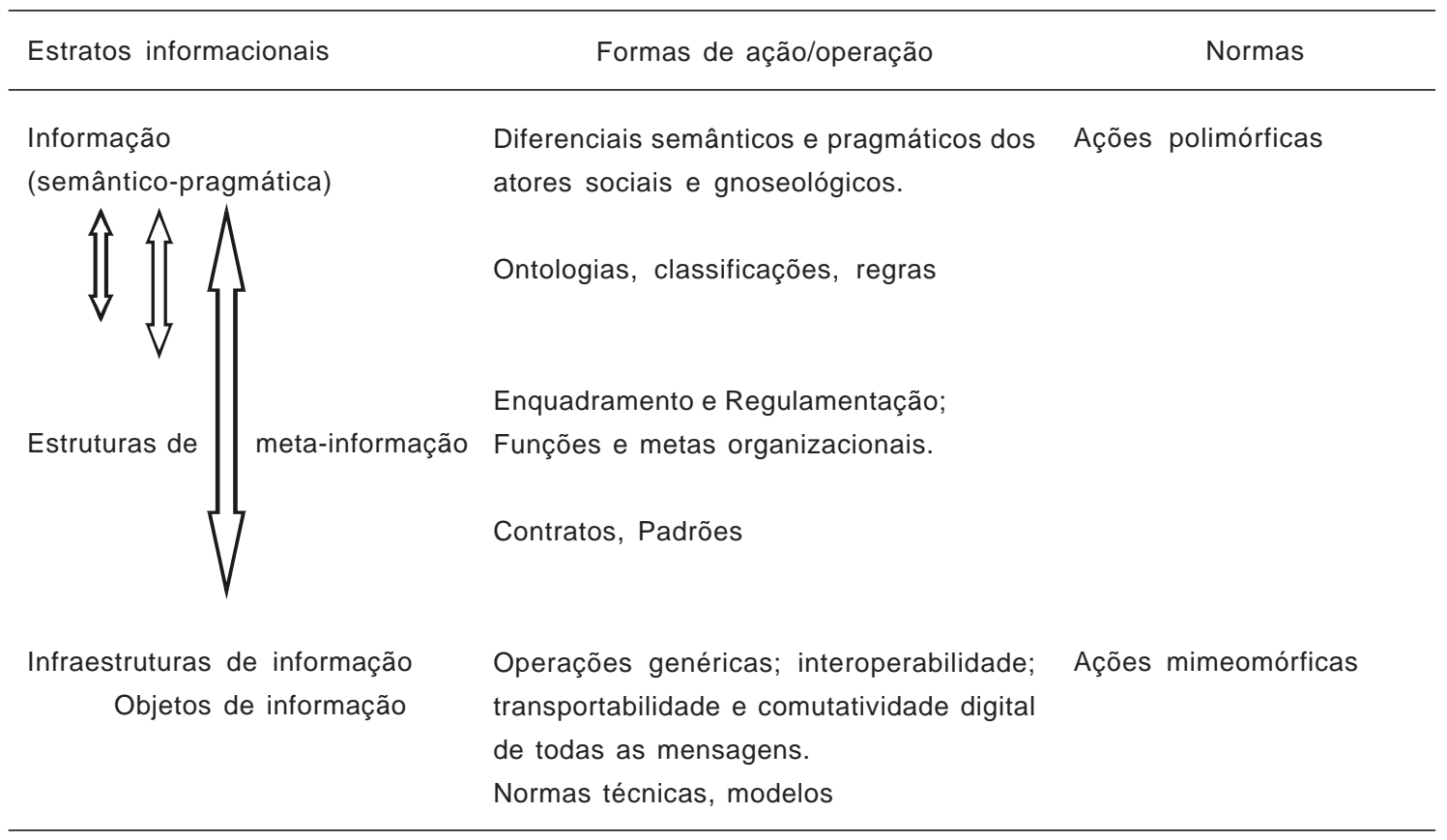

\section{As modalidades da ação de informação e suas subjetividades preferenciais}

Tomando como apoio as categorias de Collins, podemos reconhecer três modalidades de manifestação de uma ação de informação, conforme o contexto de sua constituição: uma ação de informação de mediação (quando a ação de informação fica atrelada aos fins e orientação de uma outra ação); uma ação de informação formativa (aquela que é orientada à informação não como meio mas como sua finalização); e uma ação de informação relacional (quando uma ação de informação tem como finalidade intervir numa outra ação de informação, de modo que - ainda quando de autonomia relativa - dela obtém a direção e fins) (Quadro 3).

Entendemos que quando a informação enquanto tal forma parte de uma ação de informação que intervem como mediação no contexto de outra ação social, podemos dizer que o sujeito dessa ação de informação é um "sujeito funcional”, cujas práticas e motivações serão definidas pelo contexto acional em que atua, dentro das múltiplas atividades sociais. Seu domínio de constituição é a práxis.

Quando a informação é constituída no contexto de uma ação informacional formativa, iniciando uma nova cadeia ou domínio informacional, diremos que é manifestação das ações de sujeitos sociais heurísticos ou "experimentadores", e trata-se, assim, de uma manifestação do domínio da "poiesis"; diremos que esta ação de informação é gerada por sujeitos transformadores dos modos culturais de agir e de fazer, nas artes, na política, na ciência, na indústria e no trabalho.

Quando a ação de informação tem como objeto de referência ou intervenção outra ação de informação, duplicando assim o espaço de realização de uma outra ação de informação, o qual alarga nas formas da descrição, da facilitação, do controle ou do monitoramento, falamos de ações relacionais realizadas por sujeitos articuladores ou "relacionantes", que 
executariam em grande parte uma forma de trabalho que teria a maior expansão no mundo contemporâneo: o trabalho relacional ou interativo.

Eles agiriam no domínio do "legein", da reunião e da articulação dos sujeitos e dos estratos.

Observamos, porém, não ser necessário que esses sujeitos formem categorias sociais com recrutamentos específicos; as subjetividades constituídas nos modos da práxis, da poiesis e o legein teriam antes o caráter de figuras e possibilidades que estariam em princípio ao alcance de todos os grupos sociais e indivíduos. A fixação de papéis e de modalidades de ação de informação atende à divisão social do trabalho, incluído o trabalho da cognição.

Em síntese, toda ação de informação tem uma orientação afim, mas só num caso essa finalidade é a geração de informação como potência e competência de transformação - nela mesma.

Quadro 3. Modalidades e sujeitos das ações de informação.

\begin{tabular}{|c|c|c|}
\hline Ações de Informação & Atores & Atividades \\
\hline Ação de Mediação & $\begin{array}{c}\text { Sujeitos Sociais Funcionais } \\
(\text { práxis })\end{array}$ & Atividades Sociais Múltiplas \\
\hline Ação Formativa ou Finalista & $\begin{array}{c}\text { Sujeitos Sociais Experimentadores } \\
\text { (poiesis) }\end{array}$ & $\begin{array}{c}\text { Atividades Heurísticas } \\
\text { e de Inovação }\end{array}$ \\
\hline $\begin{array}{l}\text { Ação Relacional } \\
\text { Inter- } \\
\text { Meta- }\end{array}$ & $\begin{array}{c}\text { Sujeitos Sociais Articuladores } \\
\text { e Reflexivos } \\
(\text { legein })\end{array}$ & $\begin{array}{l}\text { Atividades Sociais de } \\
\text { Monitoramento, Controle } \\
\text { e Coordenação }\end{array}$ \\
\hline Pós-mediática & & \\
\hline
\end{tabular}

Quadro 4. Teleologia das ações de informação.

\begin{tabular}{|c|c|c|c|}
\hline Ações de Informação & Atores & Atividades & Para \\
\hline Ação de Mediação & $\begin{array}{l}\text { Sujeitos Sociais Fun- } \\
\text { cionais } \\
\text { (Práxis) }\end{array}$ & $\begin{array}{l}\text { Atividades Sociais Múlti- } \\
\text { plas }\end{array}$ & $\begin{array}{l}\text { Transformar o mundo social } \\
\text { ou natural }\end{array}$ \\
\hline $\begin{array}{l}\text { Ação Formativa } \\
\text { ou Finalista }\end{array}$ & $\begin{array}{l}\text { Sujeitos Sociais } \\
\text { Experimentadores } \\
\text { (Poiesis) }\end{array}$ & $\begin{array}{l}\text { Atividades Heurísticas e } \\
\text { de Inovação }\end{array}$ & $\begin{array}{l}\text { Transformar o conhecimen- } \\
\text { to para transformar o mun- } \\
\text { do }\end{array}$ \\
\hline $\begin{array}{c}\text { Ação Relacional } \\
\text { Inter- } \\
\text { Meta- } \\
\text { Pós-mediática }\end{array}$ & $\begin{array}{l}\text { Sujeitos Sociais Arti- } \\
\text { culadores e Reflexivos } \\
\text { (Legein) }\end{array}$ & $\begin{array}{l}\text { Atividades Sociais de } \\
\text { Monitoramento, Controle e } \\
\text { Coordenação }\end{array}$ & $\begin{array}{l}\text { Transformar a informação } \\
\text { e a comunicação que orien- } \\
\text { tam o agir coletivo }\end{array}$ \\
\hline
\end{tabular}


Em nossa análise, utilizamos a representação em estratos com um objetivo: tratar de reconstruir como o ser humano, na medida em que se trata de um ser nem totalmente predeterminado por sua natureza biológica, nem um ser ficcional ou angélico e sem constrangimentos, combina ao mesmo tempo autonomia e condicionamentos sociais e materiais, em seus modos de processar e intervir em seu ambiente semiótico (Quadro 4).

Definidas por seu papel relacional num domínio de redes narrativas, sociais, técnicas e institucionais, a informação e a ação de informação só podem identificar-se e definir-se em uma cadeia de relações que tem sua especificidade no contexto social de sua constituição. Sua ancoragem nesse contexto dependerá, porém, das figuras de intersubjetividade que traçam os implicados nessa ação, e a partir das quais existe ou não um valor prático e factual nos elos que a informação estabelece entre os sujeitos e os "estados de coisas" no mundo.

É sobre esse primeiro e aproximativo quadro de descrição do escopo e da abrangência da Ciência da Informação, e conforme o estado atual das questões, que propomos a reflexão sobre a Pós-Graduação.

\section{A Pós-Graduação: disciplinaridade, interdisciplinaridade, transdisciplinaridade}

A Pós-Graduação numa área do conhecimento ficaria institucionalizada numa cartografia disciplinar mais ou menos extensa e coesa.

A compreensão do papel das disciplinas, nas formas ocidentais de produção dos conhecimentos, requer analisá-las, de modo geral, dentro dos movimentos ou processos que as definem em sua constituição sociocultural.

Uma disciplina pode ser definida como uma categoria organiza- dora do conhecimento científico: ela institui a divisão e especialização do trabalho, e responde à diversidade dos domínios que recobrem as ciências (MORIN, 2002, p.65).

Conforme Morin (2002), cada disciplina busca sua autonomia: a) pela delimitação de suas fronteiras; b) pela constituição de uma linguagem própria; c) pelas técnicas que elabora ou utiliza; c) pela construção de conceitos e teorias.

Poderíamos dizer, desenvolvendo as colocações de Edgard Morin que, se é próprio da disciplina ter seu ponto de vista diferencial que estipula o domínio de construção de seu objeto, esta só pode ter efetividade heurística se não fica cega ao campo de visão, onde apreende e compreende o conjunto das vizinhanças, ligações e solidariedades que completam e renovam a configuração de seu objeto. Seria sempre necessário que o ponto de vista não ocultasse o campo de visão.

A produção de conhecimento "disciplinar" adquire vitalidade num movimento de fechamento e abertura: se não tivessem seus momentos de delimitação e focalização de um domínio - movimento de fechamento -, os conhecimentos ficariam "fluidificados", "vagos"; mas se não mantivessem esse seu objeto como algo "extraído ou construído por processos específicos", dentro de uma rede de relações solidárias com outros objetos, tratados por outras abordagens disciplinares, dentro de todas as malhas que ligam o domínio com o universo do qual faz parte - movimento de abertura -, correriam o risco de "coisificação" desse objeto, que passaria a ser naturalizado como coisa em si - e pelo tanto, sujeito a sua permanente repetição e cópia.

Daí que se a história oficial da ciência seria a da disciplinaridade, a história não oficial seria a de constantes migrações, exportação e importação de conceitos, hibridação de domínios e abordagens, de procedimentos e teorias. 
(...) se a história oficial da ciência é da disciplinaridade, uma outra história, que lhe é ligada e inseparável, é aquela da inter-poli-transdisciplinaridade (MORIN, 2002, p.69).

$\mathrm{Na}$ "história real", as disciplinas teriam constituído um princípio de estabilização em grande escala da produção de conhecimentos científicos, sob o pano de fundo de uma ciência heterogênea, que teria perdido a idéia de um "princípio fundador", teórico ou metodológico, para ficar imersa no mundo cultural e histórico de sua emergência.

A construção disciplinar dos conhecimentos, enquanto culturais, incluiria a construção de um segundo "corpo" - reformulação do corpo pela aquisição de habilidades práticas e modos específicos de relacionar-se com o mundo, através de significados, procedimentos e instrumentos próprios. Responde, aliás, no contexto ocidental contemporâneo, às estruturas regulatórias, político-institucionais, que mantém a produção dos conhecimentos ligada às macroesferas da política e da economia.

(...) considerar as disciplinas como estruturas dinâmicas destinadas a reunir, direcionar e reproduzir as práticas sociais e técnicas essenciais para o funcionamento de uma economia política e do sistema de relações de poder que a efetivam (LENOIR, 1997).

Falar de "Física" ou "Biologia", por exemplo, não remete assim à representação do conhecimento da Física ou da Biologia em seu puro valor epistêmico, mas uma instituição que representa em nível da política científica, os interesses dos envolvidos na pesquisa e dos que são expressão direta ou ideal dos setores de demanda. A "Física", a "Biologia", além de áreas do conhecimento, passam a consistir numa "estrutura organizacional (de ordem) superior" que participa na negociação de equivalências entre critérios, interesses e objetivos dos pesquisadores e das instituições de P\&D, além de interesses e objetivos dos que se assumem porta-vozes da demanda, como as agências de fomento, agências de política econômica e outras instâncias públicas ou privadas que fornecem recursos para a pesquisa e o ensino especializado.

De fato, a verificação de uma relação de equivalência entre um valor de conhecimento (que enquanto tal seria definido pelos "critérios de validade" próprios das áreas dos conhecimentos) e outras formas de valor, acontece hoje em dia pela tradução ideal de todo valor pelo valor econômico, na medida em que esse processo de estabelecimento de equivalências, que definirá de modo imediato a provisão social de recursos para uma ou outra produção de conhecimentos, aconteça no contexto da economia de mercado.

Não é nosso assunto atual analisar os modos de constituição e funcionamento dessas cadeias avaliativas, de fomento, de regulamentação e de fiscalização, que incluem os comitês avaliadores de pares, os procedimentos de monitoramento e avaliação de agências como Capes, CNPq, Finep. Cabe lembrar, aliás, outras muitas agências reguladoras do Estado, como a Feema, a Anvisa (GONZÁLEZ DE GÓMEZ, 2001), que tanto devem monitorar e garantir processos de conversão de valor entre bens ou serviços sociais que incorporam saberes e competências altamente especializados e os interesses e demandas de seus usuários atuais e potenciais, quanto analisar controvérsias e apontar desvios na produção desses bens e serviços, assumindo-se ao mesmo tempo como instância de arbitragem competente e como expressão de uma "comunidade universal" de direitos - sujeito de demanda, uso, avaliação de custo ou benefício.

Esses poderes fáticos de "demarcação", que controlam a distribuição do tempo e do espaço acadêmico (alocação de espaço para 
programas de pesquisa, laboratórios, salas de aula, equipamentos, recursos humanos, etc.), sendo formas históricas e preferenciais de organizar os conhecimentos, não teriam logo - e conforme prévias considerações - uma natureza identitária e apriorística. Nem a Ciência da Informação nem as outras áreas e sub-áreas do conhecimento respondem assim a uma "ontologia regional" imutável que estabelece domínios e objetos de conhecimento exclusivos e excludentes.

De Wittgenstein (1996) a Kuhn (1975), a leitura das heterogeneidades e diferenciação das práticas científicas, justificaria uma nova configuração da ciência em disciplinas e especialidades; de modo paralelo, porém, a configuração disciplinar colocaria em manifesto os constantes cruzamentos e transversalidades dessas práticas entre diversas áreas do conhecimento, manifestando certa porosidade dos paradigmas ou certa hibridação de componentes que passariam a ser inter e trans-paradigmáticos.

Nas últimas décadas, pode se diferenciar duas maneiras principais de lidar com a questão. Por um lado, procura-se analisar os processos de hibridação, translação e deslocamentos com que certos conceitos, argumentos e dados, que produzem movimentos de migração entre áreas do conhecimento e geram os 'encontros interdisciplinares' (RAWSKI, 1973) e, não em poucos casos, novos espaços de especialização altamente verticalizados e complexos. De fato, processos contínuos de importação e exportação de conceitos, modelos teóricos e procedimentos metodológicos teriam acompanhado sempre a formação das especialidades, suas fissões/fusões e transformações.

Por outro lado, teríamos a demanda de conhecimentos científicos e tecnológicos a serem utilizados na resolução de problemas que identificam "zonas obscuras de ignorância", no contexto das diversas atividades sociais, como a indústria ou a saúde coletiva, gerando outras formas de articulação e reunião de saberes e práticas, que respondem melhor ao conceito de transdisciplinares.

As engenharias seriam a expressão mais constante de um conhecimento que, dirigido à intervenção sobre realidades complexas, nunca teria mantido demarcações disciplinares restritas.

É no pós-guerra, porém, quando se intensificam as relações entre o Estado, a Indústria, as Ciências e as Tecnologias, que os diversos conhecimentos que integram os programas de pesquisa passariam a ter configurações cada vez mais ricas, intensas e de maior complexidade, como nos programas de pesquisa orientados à missão.

Outros problemas e situações favorecerão a emergência de novas estruturas de relação e cooperação entre especialidades e disciplinas - além das Engenharias, teríamos assim os programas de pesquisa em Meio Ambiente, Estudos Culturais, Estudos da Mulher, entre outros.

As cadeias de produção de conhecimento ficam, aliás, mais longas e complexas não só pela diversidade de suas questões, seus temas e pontos de partida, mas também por incluir um número maior de parcerias epistêmicas e de alianças sociais. Trata-se não só de incluir os não-cientistas nas esferas de comunicação da ciência enquanto pública mas também de incluir as diferenças epistemológicas, culturais e de interesse dos sujeitos envolvidos em empreendimentos coletivos, a atuarem em instâncias específicas dos ciclos ampliados de geração e uso dos conhecimentos, junto aos cientistas.

Dentro da Comunidade Européia, um texto da Organization for Economic Cooperation and Development (OECD), de 1982, marcaria a passagem dos modelos internalistas - os quais consideram as áreas do conhecimento e suas relações a partir de questões emergentes na própria comunidade científica, estabelecendo-se figuras endógenas da interdisciplinaridade, para 
a elaboração de modelos mais complexos que focalizariam novas configurações de uma interdisciplinaridade exógena, constituída à luz de problemas emergentes na sociedade e suas necessidades práticas. Esta abordagem teria sido antecipada pela "filosofia administrativa" norte-americana da década do 60, qualificando essas novas formas de programas de pesquisa em grande escala e trans-institucionais como pesquisas "orientadas por problemas" ou "por missão".

As orientações atuais visam, nessa mesma direção, a superar tanto os dualismos internalismo-externalismo, quanto toda fórmula pré-estabelecida das estruturas de relações intersubjetivas "habilitadas" para a produção de conhecimentos e informações válidos e socialmente valiosos.

Lenoir vai diferenciar o que denominará "Programas de Pesquisa" e "Programas Disciplinares" (AMARAL, 1997). Para reconstruir as características de cada um deles, recomenda olhar: a) o lugar de produção dos conhecimentos; b) os instrumentos utilizados na construção do objeto científico ou na investigação de um fenômeno (já que de algum modo a tecnologia passa a ser o modelo do objeto); c) partir do princípio das "heterogeneidades" das "disciplinas" e das "especialidades" como locus de estruturação das práticas científicas.

Segundo Lenoir (1997), tanto os programas de pesquisa (Concentram-se na resolução de problemas; Atrelados a nichos institucionais de inovação; Grande influência de técnicas e descobertas de outras áreas; fortemente associados a uma base instrumental; O sucesso do programa de pesquisa só em parte é explicado pelo poder cognitivo da base de pesquisa desenvolvida) quanto os programas disciplinares (Preocupam-se com o desenvolvimento da disciplina; Fortemente institucionais; Ênfase no estabelecimento de papéis a serem desempenhados; facilitadores da construção de elos entre as disciplinas - tradução/transmissão de ferramentas, conceitos e técnicas para outros grupos e para áreas disciplinares vizinhas; Os construtores de disciplinas se dirigem aos programas de pesquisa para obter subsídios para atingir metas institucionais - disciplinares) partilham as mesmas dinâmicas e regras do campo científico, mas seguem diferentes orientações e objetivos.

O que nos interessa destacar, nesse texto, é que os dois programas implicam-se um com outro, constituindo uma complexa ecologia de agentes, instituições, processos e produtos dos conhecimentos.

Um regime de verdade estaria definido assim pelos Programas de Pesquisa, que competiriam entre si pela definição do campo científico, junto aos Programas Disciplinares, que competem entre si pela definição da sociedade (em seu domínio de intervenção); em nosso caso, podemos pensar na definição preferencial de agentes, organizações, técnicas, recursos, processos, artefatos e infraestruturas de informação a serem desenvolvidos e implementados nos diferentes campos da atividade social e informacional.

\section{CONSIDERA ÇÕ ES FINA IS}

A partir das reflexões anteriores, podemos inferir algumas questões - a serem futuramente melhor discutidas e analisadas.

Em primeiro lugar, nessa abordagem, a Ciência da Informação construiria seu ponto de vista no domínio epistemológico das ciências sociais (a partir da configuração ação de informação: informação), mantendo um campo de visão e solidariedades que contextualizassem a informação em suas plurais dimensões: narrativa (vizinha então à Lingüística, à História, às teorias semióticas e do discurso, à Antropologia); regulatória e estruturante (nos olhares solidários da Administração, da Sociologia, do Direito); econômica e tecnológica (em interfaces com as 
Ciências da Computação, a Telecomunicação). Mas se informação/ação de informação se constituem e modalizam propriamente nas interseções e enredamentos dessas dimensões, a Ciência da Informação mantém uma relação particular, por um lado, com os saberes que facilitam a articulação de seu ponto de vista e seu campo de visão (como os estudos da política, da comunicação, a epistemologia social, os estudos sociais da ciência, os estudos econômicos, da estética e os estudos das artes) e por outro com os que, mudando o ponto de vista, compartilham com ela o campo de visão, como a Biblioteconomia, a Arquivologia, a Museologia, mapeando desde diferentes ângulos ou com ênfases diferenciais as ecologias dos conhecimentos e das memórias sociais.

Podemos pressupor que esse posicionamento singularizaria a Ciência da Informação e a colocaria numa posição preferencial para fortalecer o olhar comunicacional e gnoseológico em processos e domínios que até agora têm sido explicitados à luz de fatores econômicos ou tecnológicos.

Ao mesmo tempo, sendo que a natureza transversal da ação de informação e da informação poderia fluidificar e horizontalizar o conhecimento constituído no campo disciplinar, o programa de pós-graduação deve ancorar seu desenvolvimento nas malhas nutrientes dos programas de pesquisa.

Nesse contexto de interação com os programas de pesquisa aconteceria o que hoje

\section{RE FER Ê N C IA S}

AMARAL, M.B. A disciplina da natureza e a natureza das disciplinas: a ciência como produção cultural: relatos de um encontro com Timothy Lenoir. Episteme, Porto Alegre, v.2, n.4, p.117-126, 1997.

COLLINS, H. M.; KUSH, M. The shape of actions: what humans and machines can do. Cambridge, Mass: MIT Press, 1999. p. 11-21. podemos denominar o "encontro transdisciplinar", estabelecendo um intercâmbio denso tanto entre os saberes e sujeitos, que constróem o ponto de vista, quanto os que enriquecem o campo de visão. Será, porém, decisivo nesse processo de conjugação de questões e finalidades, a reformulação das cadeias de implicação - intersubjetividades sociais e epistêmicas - que hoje se repartem e distanciam enquanto alocadas no modo da dissociação em um ou outro dos estratos e modalidades das ações e práticas de informação.

Como as distâncias que separam o livro, do analfabetismo, temos outros fatores que segregam sujeitos e informações: muitos são os que possuem informação sem os meios sociais de locução e transmissão; muitas as "autoridades" que desde o livro, a mídia, as bibliotecas reais e as virtuais, a escola real e virtual e as redes eletrônicas, arbitram e definem os "regimes de informação" com escassa ou nula participação dos sujeitos por eles implicados; freqüente é a análise de alguns meios, recursos e espaços funcionais, de maneira setorializada, sem suficiente análise da distribuição relativa de custos e efeitos agregados na grande escala do país, da região, dos conjuntos complexos de fontes e coletivos de demanda. Essas, enfim, seriam para nós algumas das questões relevantes e pertinentes que não deixam de lado as considerações de interesses, demandas e objetivos, dando aos estudos da Ciência da Informação a dupla referência heurística e finalística.

FOUCAULT, M. Microfísica do poder. Rio de Janeiro: Graal, 1984. p.4.

FROHMANN, B. Taking policy beyond Information Science: applying the actor network theory for connectedness: information, systems, people, organizations. In: ANNUAL CONFERENCE CANADIAN ASSOCIATION FOR INFORMATION SCIENCE, 23., Edmond, Alberta, 7-10 June 1995. 
GEERTZ, C. O Saber local. Petrópolis: Vozes, 1998. GONZÁLEZ DE GÓMEZ, M.N. Da organização do conhecimento às políticas de informação. Informare, Rio de Janeiro, v.2, n.2, p.58-66, 1996.

GONZÁLEZ DE GÓMEZ, M.N. O caráter seletivo das ações de informação. Informare, Rio de Janeiro, v.5, n.2, p.7-31, 2000.

GONZÁLEZ DE GÓMEZ, M.N. et al. Cidade, cidadania e informação: espaços e redes de informação urbana. Relatório de Pesquisa, CNPq. Brasília, 2001.

KUHN, T.S. Consideración en torno a mis críticos. In: LAKATOS,I.; MUSGRAVE, A. (Eds.). La crítica y el desarrollo del conocimiento. Barcelona: Grijalbo, 1975. p.391-454.

LENOIR, T. Registrando a ciência: os textos científicos e as materialidades da comunicação. Episteme, Porto Alegre, v.2, n.4, p.55-72, 1997.

MORIN, E. Articular os saberes. In: ALVES, N.; GARCIA, R.L. (Org.). O sentido da escola. Rio de Janeiro: DP\&A, 2002.

RAWSKI, C. Toward a theory of librarianship: papers in honor of Jesse H. Shera. New Jersey: Scarecrow, 1973.

WITTGENSTEIN, L. Investigações filosóficas. Petrópolis: Vozes, 1996. 
